
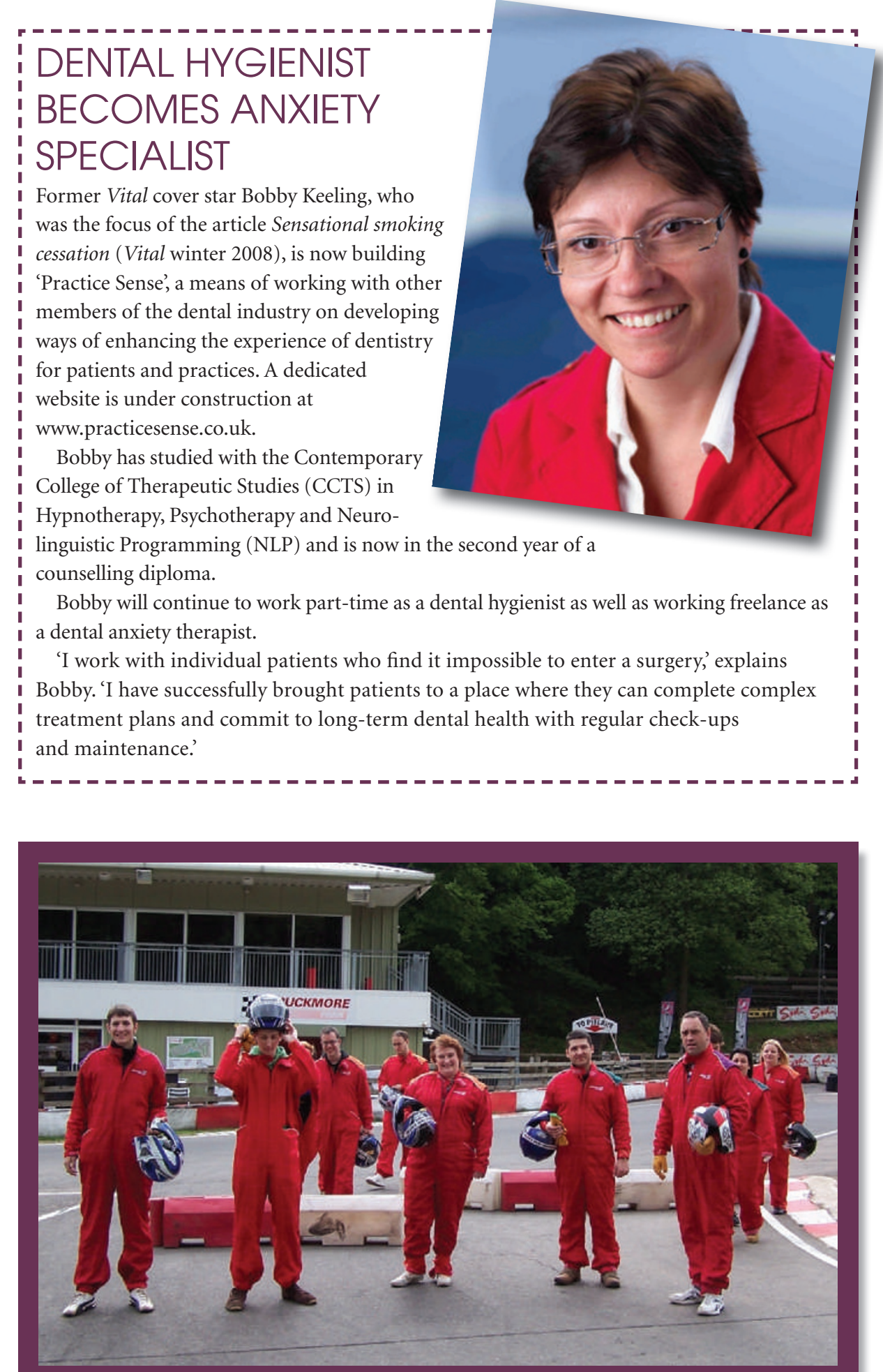

\title{
DENTAL WHOLESALERS CELEBRATE 10TH BIRTHDAY
}

Dental Sky, the dental supply company based in Ashford, Kent, is celebrating its tenth birthday this year.

The company originally opened with just three members of staff and premises with no hot water or heating, but has since moved to purpose-built modern offices and boasts a team of 27.

Staff enjoyed either a relaxing spa day or an exciting day of quad-biking and go-karting to celebrate the anniversary.

'The changes in Dental Sky have been an experience to watch,' said David 'Little Dave' Lane, who has been with the company since day one. 'It's been a privilege to be part of such a dedicated and hardworking team.' 